\title{
CORRIGENDUM
}

\section{Awareness, treatment and control of hypertension: the 'rule of halves' in an era of risk-based treatment of hypertension}

T Scheltens, ML Bots, ME Numans, DE Grobbee and AW Hoes

Journal of Human Hypertension (2007) 21, 182. doi:10.1038/sj.jhh.1002149

Correction to: Journal of Human Hypertension (2007) 21, 99-106. doi:10.1038/sj.jhh.1002123

Since the above publication, the authors have noticed an error in Table 3. The subjects sentence was incorrectly published. The correct sentence is shown here.

The authors would like to apologize for this mistake.
Table 3 Treatment of hypertension of all subjects free of CVD, aware of hypertension by thresholds of 10 and $20 \%$ cardiovascular risk

Treated N (\%) Not treated N (\%) Total N (\%)

\begin{tabular}{lccr}
\hline $0-10 \%$ & $49(49)$ & $51(51)$ & $100(100)$ \\
$10-20 \%$ & $40(62.5)$ & $24(37.5)$ & $64(100)$ \\
$420 \%$ & $85(66.4)$ & $43(33.6)$ & $141(100)$ \\
& & & \\
Total $N(\%)$ & $174(59.6)$ & $118(40.4)$ & $292(100)$
\end{tabular}

Abbreviation: CVD, cardiovascular diseases.

Subjects with $\mathrm{SBP}>180$ or $\mathrm{DBP}>100 \mathrm{~mm} \mathrm{Hg}$ were assigned to the risk category $>20 \%$. 